\title{
Vitamin D and endometriosis: Is there a correlation with disease severity?
}

\author{
Giulio Evangelisti ${ }^{1,2}$, Fabio Barra ${ }^{1,2}$, Michele Fichera ${ }^{3}$, Simone Ferrero ${ }^{1,2}$ \\ 'Academic Unit of Obstetrics and Gynaecology, IRCCS Ospedale Policlinico San Martino, Genova; ${ }^{2}$ Department of Neurosciences, Rehabilitation, \\ Ophthalmology, Genetics, Maternal and Child Health (DiNOGMI), University of Genova, Genova; ${ }^{3}$ Department of General Surgery and Medical Surgical \\ Specialties, Obstetrics and Gynecology Unit, Policlinico G. Rodolico, University of Catania, Catania, Italy
}

\section{Dear Editor}

We read with great interest the article by Baek et al. [1] entitled "Differences in 25-hydroxy vitamin $\mathrm{D}$ and vitamin D-binding protein concentrations according to the severity of endometriosis" that was recently published in this journal. In this observational study, the authors enrolled women affected by mild $(n=9)$ and advanced endometriosis $(n=7)$, as well as healthy controls $(n=16)$, and evaluated serum 25 -hydroxy vitamin $\mathrm{D}$ and vitamin $\mathrm{D}$-binding protein concentrations according to the severity of disease [1].

It is well known that vitamin D metabolism and related cellular pathways play a crucial role in the regulation of immune response activity; the actions of vitamin $D$ have been studied in many different biological settings, including autoimmune disease, tumors, and gynecological diseases such as endometriosis [2,3]. With regard to endometriosis, a benign chronic disease, previous studies have reported inconsistent findings regarding the relationship of vitamin $D$ with clinical severity; notably, in the present study, the authors reported no relationship between hormone levels and the severity of endometriosis [1].

Baek et al. [1] should be congratulated for their findings and their vitally important contribution in clarifying the role of vitamin $D$ in endometriosis, which is a controversial and complex topic. With this in

Received: September 15, 2019. Accepted: April 10, 2020

Corresponding author: Fabio Barra

Academic Unit of Obstetrics and Gynaecology, IRCCS Ospedale Policlinico San

Martino, Largo R. Benzi 10, Genova 16132, Italy

Tel: +39-1139-3349437959 Fax:+39-1139-0108932843

E-mail:fabio.barra@icloud.com

This is an Open Access article distributed under the terms of the Creative Commons Attribution Non-Commercial License (http://creativecommons.org/licenses/by-nc/4.0/) which permits unrestricted non-commercial use, distribution, and reproduction in any medium, provided the original work is properly cited. mind, we would be like to share some reflections on this study. Overall, a methodological concern may be that the authors did not precisely report whether the enrolled patients presented the same specific disease localization; in light of recent evidence, it is likely that peritoneal implants, deep-infiltrating implants, and ovarian endometriomas have some distinctive pathogenic aspects. For this reason, we suggest that the type and localization of endometriosis should be reported.

Another methodological issue is the use of the American Society for Reproductive Medicine (ASRM) classification to describe the severity of the disease. According to this classification, four stages are recognized in relation to the location, amount, depth, and size of endometriotic implants; however, this classification poorly reflects the severity of pain, other clinical symptoms, and infertility risk. Thus, although this classification is widely used in the current literature, it is considered outdated and limited in terms of its ability to describe endometriosis. Recently, new studies are being conducted to validate other classification system, such as the Enzian system; nevertheless, demand remains present for accurate new classification systems [4].

In addition, because of the small amount of cases, the authors merged stages 1-2 and 3-4 of the ASRM classification into two groups (mild and advanced endometriosis). This choice effectively creates a new subdivision, which may lead to bias in the interpretation of the study results, and at least makes it more challenging to compare their results with other studies investigating this issue.

In conclusion, the role of vitamin $D$ in endometriosis remains to be clarified, and the value of using this hormone as a serum biomarker of the extent and severity of disease remains an open question. At the moment, there are no validated biological serum, urinary, or endometrial markers that can quantify the presence and severity of endometriosis. Moreover, it would be interesting to know whether vitamin D metabolism and related cellular pathways may be a future 
therapeutic target for this benign hormone-dependent disease [5]. Further studies are needed to draw definitive conclusions on the relationship between endometriosis and vitamin D.

\section{Conflict of interest}

No potential conflict of interest relevant to this article was reported.

\section{ORCID}

Giulio Evangelisti https://orcid.org/0000-0001-8075-7916

Fabio Barra https://orcid.org/0000-0003-4117-6603

Michele Fichera https://orcid.org/0000-0001-7758-2780

Simone Ferrero https://orcid.org/0000-0003-2225-5568

\section{References}

1. Baek JC, Jo JY, Lee SM, Cho IA, Shin JK, Lee SA, et al. Differences in 25-hydroxy vitamin D and vitamin D-binding protein concentrations according to the severity of endometriosis. Clin Exp Reprod Med 2019;46:125-31.

2. Theodoratou E, Tzoulaki I, Zgaga L, loannidis JP. Vitamin D and multiple health outcomes: umbrella review of systematic reviews and meta-analyses of observational studies and randomised trials. BMJ 2014;348:g2035.

3. Ferrero S, Gillott DJ, Anserini P, Remorgida V, Price KM, Ragni N, et al. Vitamin D binding protein in endometriosis. J Soc Gynecol Investig 2005;12:272-7.

4. Haas D, Shebl O, Shamiyeh A, Oppelt P. The rASRM score and the Enzian classification for endometriosis: their strengths and weaknesses. Acta Obstet Gynecol Scand 2013;92:3-7.

5. Barra F, Grandi G, Tantari M, Scala C, Facchinetti F, Ferrero S. A comprehensive review of hormonal and biological therapies for endometriosis: latest developments. Expert Opin Biol Ther 2019;19:343-60. 